\title{
Spatial dynamics of aboveground carbon stock in urban green space: a case study of Xi'an, China
}

\author{
ZhengYang YAO ${ }^{1}$, JianJun LIU ${ }^{1 *}$, XiaoWen ZHAO ${ }^{2}$, DongFeng LONG ${ }^{2}$, Li WANG ${ }^{2}$ \\ ${ }^{1}$ College of Landscape Architecture and Arts, Northwest A\&F University, Yangling 712100, China; \\ ${ }^{2}$ College of Forestry, Northwest A\&F University, Yangling 712100, China
}

\begin{abstract}
Greenhouse gas emission of carbon dioxide $\left(\mathrm{CO}_{2}\right)$ is one of the major factors causing global climate change. Urban green space plays a key role in regulating the global carbon cycle and reducing atmospheric $\mathrm{CO}_{2}$. Quantifying the carbon stock, distribution and change of urban green space is vital to understanding the role of urban green space in the urban environment. Remote sensing is a valuable and effective tool for monitoring and estimating aboveground carbon (AGC) stock in large areas. In the present study, different remotely-sensed vegetation indices (VIs) were used to develop a regression equation between VI and AGC stock of urban green space, and the best fit model was then used to estimate the AGC stock of urban green space within the beltways of Xi'an city for the years 2004 and 2010. A map of changes in the spatial distribution patterns of AGC stock was plotted and the possible causes of these changes were analyzed. Results showed that Normalized Difference Vegetation Index (NDVI) correlated moderately well with AGC stock in urban green space. The Difference Vegetation Index (DVI), Ratio Vegetation Index (RVI), Soil Adjusted Vegetation Index (SAVI), Modified Soil Adjusted Vegetation Index (MSAVI) and Renormalized Difference Vegetative Index (RDVI) were lower correlation coefficients than NDVI. The AGC stock in the urban green space of Xi'an in 2004 and 2010 was 73,843 and 126,621 t, respectively, with an average annual growth of $8,796 \mathrm{t}$ and an average annual growth rate of $11.9 \%$. The carbon densities in 2004 and 2010 were 1.62 and $2.77 \mathrm{t} / \mathrm{hm}^{2}$, respectively. Precipitation was not an important factor to influence the changes of AGC stock in the urban green space of Xi'an. Policy orientation, major ecological greening projects such as "transplanting big trees into the city" and the World Horticultural Exposition were found to have an important impact on changes in the spatiotemporal patterns of AGC stock.
\end{abstract}

Keywords: urban green space; biomass; aboveground carbon stock; vegetation indices

Citation: ZhengYang YAO, JianJun LIU, XiaoWen ZHAO, DongFeng LONG, Li WANG. 2015. Spatial dynamics of aboveground carbon stock in urban green space: a case study of Xi'an, China. Journal of Arid Land, 7(3): 350-360. doi: 10.1007/s40333-014-0082-9

Climate change has become an important issue mainly due to the greenhouse effect caused by carbon dioxide $\left(\mathrm{CO}_{2}\right)$ emission (Jo, 2002; Sivrikaya et al., 2013). Climate change may pose a serious threat to the ecological environment (Melillo et al., 1990; Karl et al., 1997) unless measures are investigated to mitigate the rising accumulation of atmospheric $\mathrm{CO}_{2}$.

Urban green space plays an important role in reducing atmospheric $\mathrm{CO}_{2}$ (Jo and McPherson, 1995; Jo, 2002). Vegetation in urban green space can absorb $\mathrm{CO}_{2}$ in the atmosphere through photosynthesis and store excessive carbon as biomass (Nowak and Crane,
2002). Therefore, the quantification of carbon stock in urban green space can help better understand its function in reducing $\mathrm{CO}_{2}$ emission in the global carbon cycle and provide a theoretical basis for the planning and management of urban green space. Nowak (1994) quantified carbon stock and uptake by urban trees in Chicago, IL, USA and explored the effects of tree planting in urban areas on atmospheric carbon levels. Guan et al. (1998) estimated green space carbon stock in the dense urban areas of Guangzhou city, and indicated that the roles of urban vegetation in the balance of carbon and oxygen would be increased greatly if it

*Corresponding author: JianJun LIU (E-mail: 1jj@nwsuaf.edu.cn) 
could be conserved and improved in some way. McPherson (1998) quantified the benefits of the urban forests in Sacramento, CA, USA in offsetting carbon emissions from human energy consumption, and presented guidelines of urban forest management to improve these benefits. Zhao et al. (2010) evaluated the influence of the urban forests in Hangzhou city on reducing carbon emissions from industrial energy use, and showed that urban forests could play a key role in offsetting urban carbon emissions.

There are different methods for estimating vegetation carbon stock. The traditional one requires a field investigation to obtain data, which is expensive, generally labor-intensive and time-consuming. Besides, it is also unsuitable for carbon stock estimation on a landscape, regional or global scale. With the development of land surface remote sensing technology, the data derived from satellites are widely used for estimating urban forest carbon stock because this technology is the most effective means of collecting spatiotemporally continuous regional and even global data (Myeong et al., 2006; Kanniah et al., 2013). In recent years, there have been an increasing number of studies that have used satellite remote sensing images for biomass estimation. Most of these studies established models to estimate aboveground carbon (AGC) stock or aboveground biomass based on statistical relationships established with field survey data and vegetation indices (VIs) (Myeong et al., 2006; Li et al., 2013; Yan et al., 2013). There are many VIs, such as the ratio vegetation index (RVI) (Birth and McVey, 1968), the normalized difference vegetation index (NDVI) (Rouse et al., 1974), the modified soil adjusted vegetation index (MSAVI) (Qi et al., 1994) and the enhanced vegetation index (EVI) (Huete et al., 1997), among which NDVI is the most widely used one. However, the relationship between NDVI and biomass is not as strong for high-biomass regions due to the saturation of NDVI (Wang et al., 2005). Previous studies suggested that RVI provides valuable information about vegetation biomass (Schlerf et al., 2005). RVI is especially sensitive to high-biomass vegetation. MSAVI was proposed to reduce background influences (Huete et al., 1997), and it may be useful for sparsely vegetated areas.
Current international researches on carbon stock estimation in urban green space mainly focus on carbon stock of trees. Few consider the carbon stock of shrubs and herbs. Shrubs and herbs are also important contributors to urban green space (Jo and McPherson, 1995). More comprehensive studies that quantify carbon stock in urban green space vegetation (trees, shrubs and herbs) are required to improve the understanding of carbon cycling in urban green space.

The objectives of this study were to develop an estimation model from a univariate model that relates spectrally derived vegetation indices and AGC stock, and estimate the AGC stock in the urban green space of Xi'an in 2004 and 2010.

\section{Study area}

Xi'an is an important city in western China. It is located at a coordinate range of $107^{\circ} 40^{\prime}-109^{\circ} 49^{\prime} \mathrm{E}$ and $33^{\circ} 39^{\prime}-34^{\circ} 45^{\prime} \mathrm{N}$ in the middle of the Guanzhong Plain, south of Weihe River and north of Qinling Mountains. It has a temperate, semi-moist continental monsoon climate with four distinct seasons. The average length of the annual frost-free period is 226 days. The monthly average temperature is $0.4^{\circ} \mathrm{C}$ in January and $26.6^{\circ} \mathrm{C}$ in July, with an annual average temperature of $13.3^{\circ} \mathrm{C}$. The average annual precipitation and humidity are $613.7 \mathrm{~mm}$ and $6.96 \%$, respectively. The altitude ranges from 410 to $420 \mathrm{~m}$. The study area is inside the beltways surrounding Xi' an and covering an area of approximately $457 \mathrm{~km}^{2}$ (Fig. 1). The major tree species of the study area were Platanus orientalis (age: 15-40 a), Sophora japonica (age: 10-30 a), Ligustrum lucidum (age: 5-20 a), Koelreuteria paniculata (age: 5-20 a), Ginkgo biloba (age: 10-40 a), Pinus tabuliformis (age: 15-45 a), Populus tomentosa (age: 5-25 a), etc. The most common shrub species were Ligustrum quihoui (basal diameter: 0.4-3.5 cm), Buxus bodinieri (basal diameter: 0.35-1.8 cm), Berberis thunbergii var. atropurpurea (basal diameter: 0.3-1.5 cm), Buxus megistophylla (basal diameter: 0.8-10.5 cm), Photinia serrulata (basal diameter: 0.5-9.5 cm), Pittosporum tobira (basal diameter: $1.8-12.5 \mathrm{~cm}$ ), all of which accounted for more than 


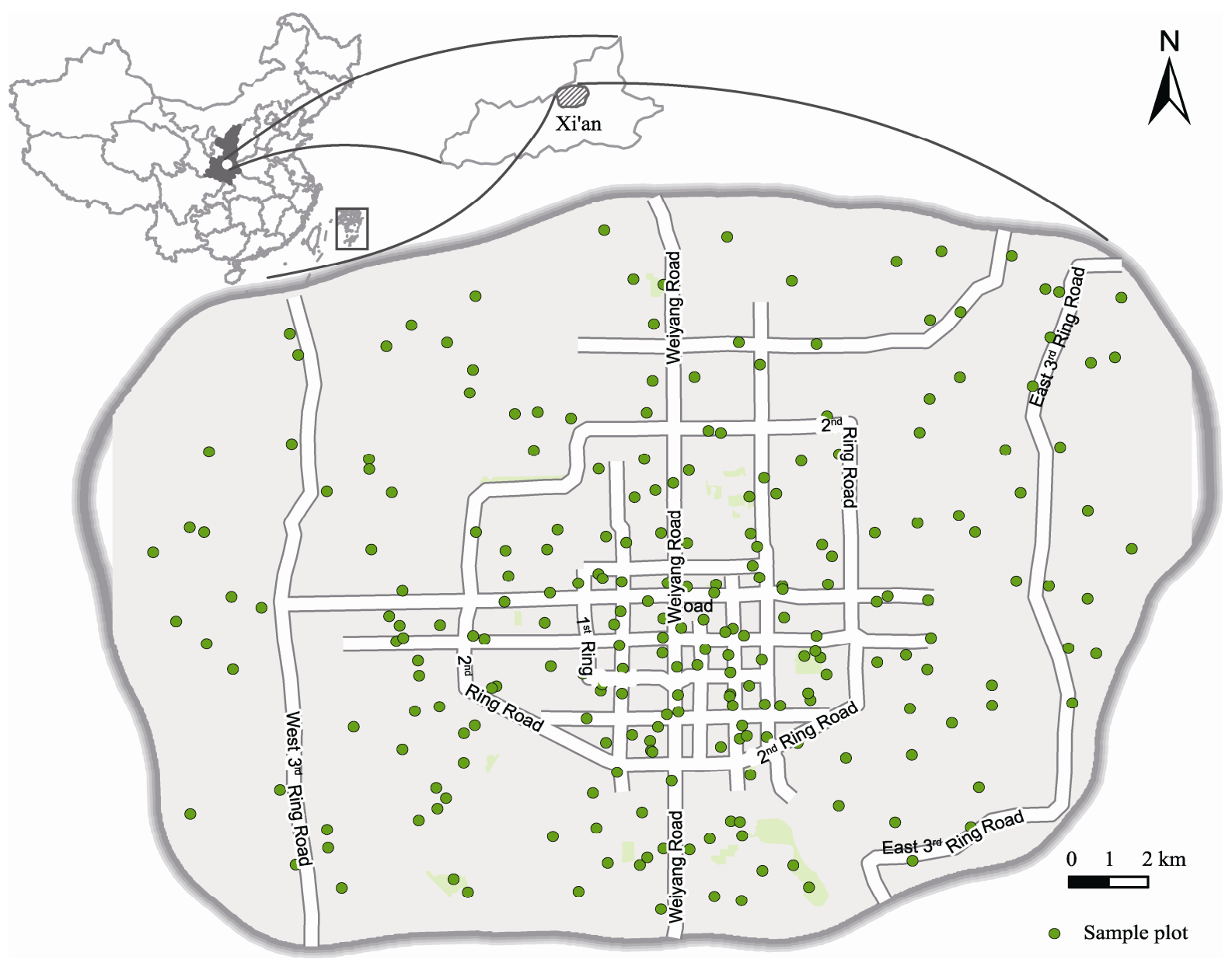

Fig. 1 Sketch map showing the boundary of Xi'an beltways and the sample plots in the study area

$80 \%$ of the total shrubs in the city. The herb species were mainly made up of Poa annua, Trifolium repens and Ophiopogon japonicus. In the urban green space of Xi'an, the major plantation structure were tree+shrub+herb, tree+herb, shrub+ herb, tree, shrub and lawn.

\section{Methods}

\subsection{Remote sensing data}

$\mathrm{TM} / \mathrm{ETM}+$ sensors on board Landsat satellites have high spatial resolution (30-m pixel size). Landsat TM images were used as a remote sensing data source to estimate AGC stock of urban green space. In the present study, the two sets of images were taken on 16 June 2004 and 17 June 2010 (downloaded from the NASA website), track number $127 / 36$. Then, a topographic map at a scale of 1:50,000 was used for geometric correction of the remote sensing data, and a nearest neighbor interpolation method was adopted to resample the pixels at a grid size of $30 \mathrm{~m} \times 30 \mathrm{~m}$, with image registration error controlled within 0.5 pixels. Fast Line-of-sight Atmospheric Analysis of Hypercubes (FLAASH) atmospheric correction was performed for radiometric correction of the images.

\subsection{Sampling design and data collection}

A total of 240 quadrats within the beltways surrounding Xi'an (19 of which contain no vegetation) were randomly generated in GIS prior to starting the field survey (Fig. 1). A field survey was conducted between 10 June and 20 June in 2010. The quadrat size was set to $30 \mathrm{~m} \times 30 \mathrm{~m}$. The central locations of the quadrats were positioned by using GPS. The following information was collected and recorded for each plant in the quadrats: for trees, the species, the number of each species, diameter at breast height $(\mathrm{DBH})$ and height; 
for shrubs, the species, the number of each species, basal diameter, crown diameter and height; for herbs, the species and area (If the shape of herb was regular, then the area of herb was calculated by using a tape; if not, the area was calculated by estimating the percentage of the quadrat it accounted for).

\subsection{Carbon stock in urban green space}

The aboveground biomass of trees was estimated using allometric models; if there was no corresponding biomass model to be used as reference, then the model for other species in the same genus, the same family or a unified model for conifers or broadleaf trees was used instead (Nowak, 1993; Table 1). The biomass of the major shrubs was estimated using regression models established with the sample data by the author himself (Table 2). If there was no corresponding model for an individual shrub species, then a model for other species in the same genus or family was used instead. As a last resort, a unified model for tree-like shrub species or typical shrub species was used (Table 2). For the estimation of herbal biomass, in each quadrat that contained herbs, three $0.5 \mathrm{~m} \times 0.5 \mathrm{~m}$ small quadrats were selected, and aboveground herbal biomass was determined by clipping in each small quadrat, drying and weighing all herbaceous material on three $0.25 \mathrm{~m}^{2}$ subplots within each plot. Values were averaged among the three subplots and expressed as $\mathrm{g} / \mathrm{m}^{2}$. And then, the herbal biomass of the entire quadrat was estimated (Johnston et al., 1996).

By forest-derived biomass equations, open-grown trees tend to have less above-ground biomass than forest-grown trees of the same diameter at breast height (Nowak, 1994). To adjust for this difference, biomass results for open-grown urban trees were multiplied by a factor of 0.8 (Nowak, 1994). In this study, all the allometric models of trees were developed from forest-grown trees.

The carbon stock of trees and shrubs were obtained by multiplying biomass with a carbon conversion coefficient of 0.5 (USDA Forest Products Laboratory, 1952; Chow and Rolfe, 1989; Jo, 2002; Nowak and Crane, 2002; Houghton, 2005); the carbon stock of herbs was obtained by multiplying biomass with a carbon conversion coefficient of 0.45 (Olson, 1970; Ajtay et al., 1979).
Table 1 Equations used to calculate aboveground biomass of trees

\begin{tabular}{|c|c|c|}
\hline Tree species & Equation & Reference \\
\hline \multirow{3}{*}{$\begin{array}{l}\text { Pinus } \\
\text { tabuliformis }\end{array}$} & $\ln W_{\mathrm{S}}=0.8446+0.6640 \ln \left(D^{2} H\right)$ & \multirow{3}{*}{ Мa, 1989} \\
\hline & $W_{\mathrm{B}}=0.2754+0.9220 \ln \left(D^{2} H\right)$ & \\
\hline & $\ln W_{\mathrm{L}}=0.3485+0.8330 \ln \left(D^{2} H\right)$ & \\
\hline \multirow{2}{*}{$\begin{array}{l}\text { Picea asperata, } \\
\text { Abies fabri }\end{array}$} & $W_{\mathrm{T}}=0.067732\left(D^{2} H\right)^{0.865949}$ & \multirow[t]{2}{*}{$\begin{array}{l}\text { Li and Lei, } \\
\quad 2010\end{array}$} \\
\hline & $W_{\mathrm{S}}=0.0130596\left(D^{2} H\right)^{0.9437920}$ & \\
\hline \multirow{4}{*}{$\begin{array}{l}\text { Metasequoia } \\
\text { glyptostroboides }\end{array}$} & $W_{\mathrm{B}}=0.0622883\left(D^{2} H\right)^{0.6761058}$ & \multirow{3}{*}{$\begin{array}{l}\text { Li et al., } \\
1996\end{array}$} \\
\hline & $W_{\mathrm{P}}=0.0045843\left(D^{2} H\right)^{0.8487557}$ & \\
\hline & $W_{\mathrm{L}}=0.0140282\left(D^{2} H\right)^{0.6263953}$ & \\
\hline & $W_{\mathrm{S}}=131.87\left(D^{2} H\right)^{0.5969}$ & \multirow{5}{*}{$\begin{array}{l}\text { Chang et } \\
\text { al., } 1997\end{array}$} \\
\hline \multirow[t]{4}{*}{ Sabina chinensis } & $\begin{array}{l}W_{\mathrm{B}}=27.40\left(D^{2} H\right)^{0.5973}+49.65\left(D^{2} H\right)^{0.5975}+ \\
5.51\left(D^{2} H\right)^{0.5879}\end{array}$ & \\
\hline & $W_{\mathrm{P}}=36.32\left(D^{2} H\right)^{0.6758}$ & \\
\hline & $W_{\mathrm{L}}=37.87\left(D^{2} H\right)^{0.5976}$ & \\
\hline & $W_{\mathrm{S}}=0.312+0.016 D^{2} H$ & \\
\hline \multirow[t]{3}{*}{$\begin{array}{l}\text { Robinia } \\
\text { pseudoacacia }\end{array}$} & $W_{\mathrm{B}}=0.161+0.003 D^{2} H$ & \multirow[t]{2}{*}{$\begin{array}{l}\text { He et al., } \\
2007\end{array}$} \\
\hline & $W_{\mathrm{L}}=0.091+0.003 D^{2} H$ & \\
\hline & $W_{\mathrm{S}}=0.437+0.004 D^{2} H$ & \multirow{3}{*}{$\begin{array}{l}\text { He et al., } \\
2007\end{array}$} \\
\hline \multirow[t]{3}{*}{$\begin{array}{l}\text { Ligustrum } \\
\text { lucidum }\end{array}$} & $W_{\mathrm{B}}=0.075+0.004 D^{2} H$ & \\
\hline & $W_{\mathrm{L}}=0.163+0.002 D^{2} H$ & \\
\hline & $W_{\mathrm{S}}=0.587+0.006 D^{2} H$ & \multirow{3}{*}{$\begin{array}{l}\text { He et al., } \\
2007\end{array}$} \\
\hline \multirow[t]{3}{*}{$\begin{array}{l}\text { Koelreuteria } \\
\text { paniculata }\end{array}$} & $W_{\mathrm{B}}=0.059+0.001 D^{2} H$ & \\
\hline & $W_{\mathrm{L}}=0.029+0.001 D^{2} H$ & \\
\hline & $W_{\mathrm{S}}=0.044+0.042 D^{2} H$ & \multirow{3}{*}{$\begin{array}{l}\text { He et al., } \\
2007\end{array}$} \\
\hline \multirow[t]{3}{*}{ Ginkgo biloba } & $W_{\mathrm{B}}=-0.011+0.005 D^{2} H$ & \\
\hline & $W_{\mathrm{L}}=-0.820+0.040 D^{2} H$ & \\
\hline & $W_{\mathrm{S}}=33.88386\left(D^{2} H\right)^{0.87652}$ & \multirow{4}{*}{$\begin{array}{l}\text { Zhu et al., } \\
1988\end{array}$} \\
\hline \multirow{3}{*}{$\begin{array}{l}\text { Populus } \\
\text { davidiana }\end{array}$} & $W_{\mathrm{B}}=0.42042\left(D^{2} H\right)^{1.38703}$ & \\
\hline & $W_{\mathrm{P}}=5.93658\left(D^{2} H\right)^{0.94024}$ & \\
\hline & $W_{\mathrm{L}}=0.31081\left(D^{2} H\right)^{1.20433}$ & \\
\hline \multirow{3}{*}{$\begin{array}{l}\text { Populus } \\
\text { tomentosa }\end{array}$} & $W_{\mathrm{S}}=0.016\left(D^{2} H\right)^{1.007}$ & \multirow{3}{*}{ Yang, 2011} \\
\hline & $W_{\mathrm{B}}=0.006 D^{1.99} H^{1.002}$ & \\
\hline & $W_{\mathrm{L}}=0.002\left(D^{2} H\right)^{0.975}$ & \\
\hline Paulownia & $\lg W_{\mathrm{T}}=0.9689 \lg D^{2} H-1.6329$ & $\begin{array}{l}\text { Lu et al., } \\
1990\end{array}$ \\
\hline \multirow{3}{*}{ Other conifers } & $W_{\mathrm{S}}=0.0254\left(D^{2} H\right)^{0.948}$ & \multirow{3}{*}{$\begin{array}{l}\text { Wang et al., } \\
\quad 1996\end{array}$} \\
\hline & $W_{\mathrm{B}}=0.00556\left(D^{2} H\right)^{0.924}$ & \\
\hline & $W_{\mathrm{L}}=\left(W_{\mathrm{S}}+W_{\mathrm{B}}\right) / 7.5+0.0125\left(W_{\mathrm{S}}+W_{\mathrm{B}}\right)$ & \\
\hline \multirow{3}{*}{$\begin{array}{l}\text { Other broadleaf } \\
\text { trees }\end{array}$} & $W_{\mathrm{S}}=0.0396\left(D^{2} H\right)^{0.933}$ & \multirow{3}{*}{$\begin{array}{l}\text { Liu et al., } \\
2000\end{array}$} \\
\hline & $W_{\mathrm{B}}=0.0055\left(D^{2} H\right)^{1.027}$ & \\
\hline & $W_{\mathrm{L}}=\left(W_{\mathrm{S}}+W_{\mathrm{B}}\right) / 23.8+0.0333\left(W_{\mathrm{S}}+W_{\mathrm{B}}\right)$ & \\
\hline
\end{tabular}

Note: $W_{\mathrm{S}}, W_{\mathrm{B}}, W_{\mathrm{P}}, W_{\mathrm{L}}$ and $W_{\mathrm{T}}$ represent the biomass of stem, branch, bark, leaf and aboveground, respectively. $D$ and $H$ represent diameter at breast height and height, respectively. 
Table 2 Equations used to calculate aboveground biomass of shrubs

\begin{tabular}{|c|c|c|c|c|c|c|}
\hline \multirow{2}{*}{ Shrub species } & \multirow{2}{*}{ Equation } & \multicolumn{2}{|c|}{ Parameter } & \multirow{2}{*}{$R^{2}$} & \multirow{2}{*}{$P$} & \multirow{2}{*}{ Reference } \\
\hline & & a & $\mathrm{b}$ & & & \\
\hline \multirow{2}{*}{ Photinia serrulata } & $W_{\mathrm{B}}=\mathrm{a}\left(D^{2} H\right)^{\mathrm{b}}$ & 0.310 & 1.097 & 0.985 & $<0.001$ & \\
\hline & $W_{\mathrm{L}}=\mathrm{a}\left(D^{2} H\right)^{\mathrm{b}}$ & 0.264 & 0.916 & 0.986 & $<0.001$ & \\
\hline \multirow{2}{*}{ Pittosporum tobira } & $W_{\mathrm{B}}=\mathrm{a}\left(V_{\mathrm{c}}\right)^{\mathrm{b}}$ & 765.073 & 0.824 & 0.991 & $<0.001$ & \\
\hline & $W_{\mathrm{L}}=\mathrm{a}\left(D^{2} H\right)^{\mathrm{b}}$ & 2.958 & 0.607 & 0.911 & $<0.001$ & \\
\hline \multirow{2}{*}{ Hibiscus syriacus } & $W_{\mathrm{B}}=\mathrm{a}\left(V_{\mathrm{c}}\right)^{\mathrm{b}}$ & 108.688 & 1.693 & 0.984 & $<0.001$ & \\
\hline & $W_{\mathrm{L}}=\mathrm{a}(C H)^{\mathrm{b}}$ & 18.925 & 1.565 & 0.969 & $<0.001$ & \\
\hline \multirow{2}{*}{ Nandina domestica } & $W_{\mathrm{B}}=\mathrm{a}(C H)^{\mathrm{b}}$ & 75.700 & 1.110 & 0.980 & $<0.001$ & \\
\hline & $W_{\mathrm{L}}=\mathrm{a}+\mathrm{b} \ln (H)$ & 11.109 & 17.911 & 0.971 & $<0.001$ & \\
\hline \multirow{2}{*}{ Lagerstroemia indica } & $W_{\mathrm{B}}=\mathrm{a} H^{\mathrm{b}}$ & 30.213 & 6.318 & 0.987 & $<0.001$ & \\
\hline & $W_{\mathrm{L}}=\mathrm{a} H^{\mathrm{b}}$ & 6.656 & 5.065 & 0.994 & $<0.001$ & \\
\hline \multirow{2}{*}{ Syringa oblata } & $W_{\mathrm{B}}=\mathrm{a}\left(D^{2} H\right)^{\mathrm{b}}$ & 0.876 & 0.894 & 0.988 & $<0.001$ & \\
\hline & $W_{\mathrm{L}}=\mathrm{a}\left(D^{2} H\right)^{\mathrm{b}}$ & 0.683 & 0.715 & 0.988 & $<0.001$ & \\
\hline \multirow{2}{*}{ Forsythia suspensa } & $W_{\mathrm{B}}=\mathrm{a}\left(D^{2} H\right)^{\mathrm{b}}$ & 0.385 & 1.025 & 0.997 & $<0.001$ & \\
\hline & $W_{\mathrm{L}}=\mathrm{a}\left(D^{2} H\right)^{\mathrm{b}}$ & 0.187 & 0.868 & 0.985 & $<0.001$ & \\
\hline Ligustrum quihoui & $\begin{array}{l}W_{\mathrm{B}}=26.332(C H)^{0.666} \\
W_{\mathrm{L}}=14.646 C^{1.164}\end{array}$ & & & & & Yao and Liu, 2014 \\
\hline Buxus bodinieri & $\begin{array}{l}W_{\mathrm{B}}=262.879(\mathrm{CH})^{1.546} \\
W_{\mathrm{L}}=224.662(\mathrm{CH})^{1.364}\end{array}$ & & & & & Yao and Liu, 2014 \\
\hline $\begin{array}{l}\text { Berberis thunbergii var. atro- } \\
\text { purpurea }\end{array}$ & $\begin{array}{l}W_{\mathrm{B}}=73.468\left(A_{\mathrm{c}}\right)^{0.766} \\
W_{\mathrm{L}}=3.340\left(A_{\mathrm{c}}\right)^{0.465}\end{array}$ & & & & & Yao and Liu, 2014 \\
\hline Buxus megistophylla & $\begin{array}{l}W_{\mathrm{B}}=15.572 D^{1.325} \\
W_{\mathrm{L}}=20.649+9.047 \ln (C H)\end{array}$ & & & & & Yao and Liu, 2014 \\
\hline Sorbaria sorbifolia & $W_{\mathrm{T}}=68.018\left(A_{\mathrm{c}}\right)^{1.021}$ & & & & & Li et al., 2010 \\
\hline Euonymus alatus & $W_{\mathrm{T}}=0.095 D^{2.655}$ & & & & & Li et al., 2010 \\
\hline Tree-like shrub species & $W_{\mathrm{T}}=0.182 D^{2.487}$ & & & & & Li et al., 2010 \\
\hline Typical shrub species & $W_{\mathrm{T}}=100.71\left(A_{\mathrm{c}}\right)^{0.925}$ & & & & & Li et al., 2010 \\
\hline
\end{tabular}

Note: $W_{\mathrm{B}}, W_{\mathrm{L}}$ and $W_{\mathrm{T}}$ represent the biomass of branch, leaf and aboveground, respectively. $D, C$ and $H$ represent basal diameter, crown diameter and height, respectively. $A_{\mathrm{c}}=\Pi C_{1} C_{2} / 4, V_{\mathrm{c}}=A_{\mathrm{c}} H$.

\subsection{Model development}

VIs are usually a single number derived from the spectral reflectance of two or more wavebands (Ji and Peters, 2007). VIs have a good proportional relation to biophysical parameters, which are often referred to as the "biomass index". Hundreds of remote-sensing-based VIs have been developed and used in various fields of geoscience (Barati et al., 2011). Regression equations are used to establish a functional relationship based on field survey samples and the VIs, using various linear and nonlinear equations. Of the 240 field plots, 60 were randomly selected and reserved for model evaluation. The remaining 180 quadrats were used for developing the model.

In the study, six frequently used VIs were adopted to establish models of AGC stock estimation. The formulae used for calculation are shown in Table 3.
Table 3 Formulae for calculating vegetation indices in the study

\begin{tabular}{cl}
\hline Index & \multicolumn{1}{c}{ Formula } \\
\hline NDVI & $($ NIR-RED $) /(\mathrm{NIR}+\mathrm{RED})$ \\
DVI & NIR-RED \\
RVI & NIR/RED \\
SAVI & $(\mathrm{NIR}-\mathrm{RED})(1+\mathrm{L}) /(\mathrm{NIR}+\mathrm{RED}+\mathrm{L}), \mathrm{L}=0.5$ \\
MSAVI & $\left(2 \times \mathrm{NIR}+1-\left[(2 \times \mathrm{NIR}+1)^{2}-8 \times(\mathrm{NIR}-\mathrm{RED})\right]^{1 / 2}\right) / 2$ \\
RDVI & $(\mathrm{NIR}-\mathrm{RED}) /(\mathrm{NIR}+\mathrm{RED})^{1 / 2}$ \\
\hline
\end{tabular}

Note: NIR and RED represent the reflectance of near infrared and red bands, respectively. $\mathrm{L}$ is a soil adjustment factor.

Based on the relationship between VI and AGC stock estimated from the field, one optimal estimation model with the highest $R^{2}$ and the best fit was selected to estimate AGC stock for the entire study area.

\subsection{Relative radiometric correction}

Due to the constraints of local weather conditions to 
satellite imaging quality, the Landsat images used in the same phase might have different radiometric data (Du et al., 2002). Radiometric normalization is needed to monitor the dynamic changes of this region by using spectral information from remote sensing images collected for the same region at different dates. Radiometric normalization effectively reduces or eliminates the effects of differences in imaging conditions, thereby eliminating errors in dynamic monitoring. In a relative radiometric correction, one image is used as the reference image to adjust the radiometric characteristics of the other images so that the radiometric characteristics of the two images are the same. In this study, the pseudo-invariant feature method proposed by Schott et al. (1988) has been adopted for the relative radiometric correction of the two sets of images.

In the Schott pseudo-invariant feature method, the pseudo-invariant features are first extracted from the images. After the points for the pseudo-invariant features are determined, the reflectance of these points is extracted to establish the regression equations between the reference image and the image to be corrected in each band. Pseudo-invariant features refer to ground targets with reflectance that basically does not change with changing external conditions. Their reflection coefficients are independent of the season or biological and weather conditions at the time of imaging, and their spatial locations, e.g. buildings, roads and deep waters, are fixed. The key to the pseudo-invariant feature method is the selection of the points for the pseudo-invariant features. In the present study, a threshold method was adopted to improve the original method, and 2,295 points were selected. Using the reflectance of these points, the values of the parameters in Eq. 1 were acquired, and a linear relationship was derived between the two images collected at the two dates in the red band and near infrared band (Table 4). Then, this linear equation was used to complete the relative radiometric correction of the image collected in 2004.

$$
\rho_{\text {ref }}=a \rho_{s u b}+b .
$$

Where $\rho_{\text {ref }}$ is the reflectance of a point for a pseudoinvariant feature in the reference image; $\rho_{s u b}$ is the reflectance of a point for a pseudo-invariant feature in the image to be corrected; and $a$ and $b$ are the parameters in the linear equation, i.e. gain and offset, respectively.
Table 4 The scene normalization coefficients and the correction statistics for the subject image in 2004

\begin{tabular}{ccc}
\hline Coefficient & Band $_{\text {RED }}$ & Band $_{\text {NIR }}$ \\
\hline$a$ & 1.0137 & 0.9580 \\
$b$ & -0.0022 & 0.0101 \\
$R^{2}$ & 0.9808 & 0.9577 \\
\hline
\end{tabular}

\subsection{Total AGC stock estimation in urban green space}

The best fit regression equation was used to estimate the AGC stock in the urban green space of Xi'an city in 2004 and 2010. The temporal and spatial distributions of AGC stock were mapped with ArcGIS 9.3. Furthermore, the potential causes of AGC stock changes were analyzed. All analyses were conducted by using ArcGIS (version 9.3, ESRI), ENVI 5.0 and SPSS 18.0.

\section{Results and discussion}

\subsection{Estimation model for AGC stock}

The statistical models were developed by using VIs and field survey samples (Table 5). The coefficient of determination of AGC-NDVI was the highest at $R^{2}=0.71$, while the coefficient of determination of AGC-DVI was the lowest at $R^{2}=0.67$ (Table 5). Therefore, NDVI was a relatively optimal vegetation index as the input variable for AGC stock estimation in urban green space.

Table 5 Statistical models for aboveground carbon (AGC) stock estimation in urban green space

\begin{tabular}{clcc}
\hline Input variable & \multicolumn{1}{c}{ Model } & $R^{2}$ & $F$ \\
\hline NDVI & $y=6,445.014 x^{2.390}$ & 0.71 & 403.4 \\
DVI & $y=7,409.621 x-323.655$ & 0.67 & 327.6 \\
RVI & $y=-129.123 x^{2}+1,270.074 x-1,416.890$ & 0.68 & 174.0 \\
SAVI & $y=14,803.013 x^{2.261}$ & 0.69 & 364.6 \\
MSAVI & $y=14,686.578 x^{2.117}$ & 0.68 & 347.4 \\
RDVI & $y=17,050.833 x^{2.280}$ & 0.69 & 370.8 \\
\hline Note: Correlation is significant at the 0.01 level.
\end{tabular}

In order to validate the fitted equation, data obtained from the 60 quadrats not included in the model construction were compared with that predicted using the model, and it was found that the two sets of data had a strong correlation, with a correlation coefficient of 0.86 (Fig. 2). 


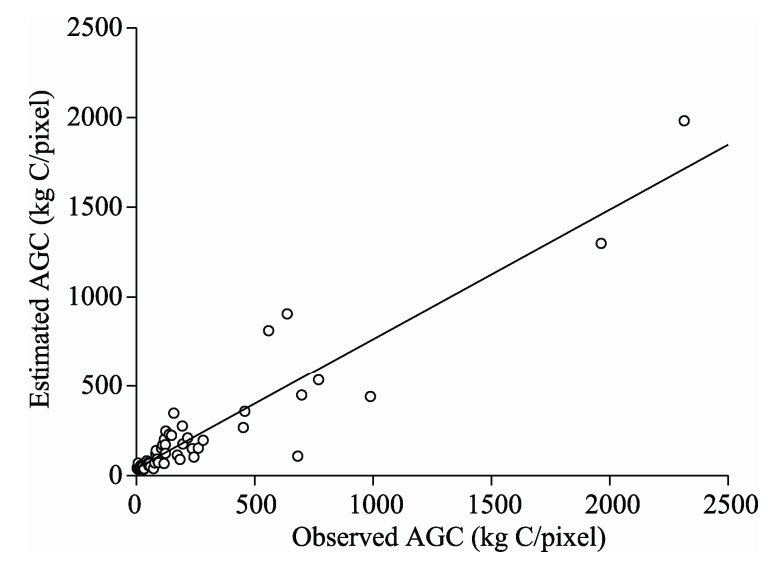

Fig. 2 Correlation between predicted aboveground carbon (AGC) stock from the AGC-NDVI estimation model and measured AGC stock from field data $(n=60, P<0.01)$

Results of the study showed that NDVI correlated moderately well $\left(R^{2}=0.71\right)$ with AGC stock in urban green space. The rest of the vegetation indices (DVI, RVI, SAVI, MSAVI and RDVI) had lower correlation coefficients than NDVI. SAVI and RDVI provided better estimation accuracy than DVI, RVI and MSAVI. Theoretically, different VIs may give different values based on different spectral bands and formulae utilized. The result was similar to a previous study in which Schlerf et al. (2005) suggested that RVI is especially sensitive to high vegetation densities. NDVI is the most widely applied VI in vegetation biomass estimation. Nevertheless, numerous studies have shown that NDVI is saturated in areas with high vegetation cover (Baret and Guyot, 1991; Jiang et al., 2008). However, this limitation was not significant here since the study area was an urban area where green space canopy density is low. Therefore, it seems that NDVI is relatively suitable for the area of the present study. NDVI was found to have limitations because of its sensitivity to different substrates (Huete, 1988). SAVI was proposed to reduce the inherent sensitivity of NDVI to varying substrates (Huete, 1988). MSAVI is designed to correct a weakness in SAVI in how vegetation responds as it moves away from the soil line (Qi et al., 1994), and it may be useful for sparsely vegetated areas. Yan et al. (2013) indicated that MSAVI and SAVI showed relatively higher correlations with aboveground biomass than NDVI in $\mathrm{Mu}$ Us Sandy Land. In previous studies estimating the carbon storage of urban forests, it was found that NDVI is a valuable tool (Myeong et al., 2006; Kanniah et al., 2013). The present study suggested that NDVI is a useful remotely sensed spectral vegetation index to detect the AGC stock of urban green space.

\subsection{Spatiotemporal distribution characteristics of AGC stock}

With the AGC-NDVI model, total and mean AGC stocks in the urban green space of Xi'an in 2004 and 2010 were obtained (Table 6). From 2004 to 2010, the total urban green space AGC stock in Xi'an increased from 73,843 to $126,621 \mathrm{t}$, with a mean annual growth of $8,796 \mathrm{t}$ and a mean annual compound growth rate of $11.9 \%$; evidencing that AGC stock of urban green space increased dramatically over those six years.

Table 6 AGC stock within the boundary of Xi'an beltways from 2004 to 2010

\begin{tabular}{ccc}
\hline Period & Total AGC (t) & Average AGC $\left(\mathrm{t} / \mathrm{hm}^{2}\right)$ \\
\hline 2004 & 73,843 & 1.62 \\
2010 & 126,621 & 2.77 \\
\hline
\end{tabular}

Figures 3 and 4 showed the spatial distributions of AGC stock in urban green space within the beltways surrounding Xi'an in 2004 and 2010, and the changes in urban green space AGC stock from 2004 to 2010, respectively. As shown by the histograms of the AGC values in Fig. 3, most AGC values of urban green space in the study area in 2010 were in the range of $0.0-1.0 \mathrm{t} / \mathrm{hm}^{2}$, and the number of AGC values over $1.0 \mathrm{t} / \mathrm{hm}^{2}$ greatly increased compared to 2004. As illustrated in Fig. 4, AGC stock in the northwest, northeast, southwest and southeast increased notably from 2004 to 2010, and in part of the northeast region the AGC stock decreased to a certain extent, possibly due to the construction of the Chan-Ba Ecological District, which has a large area of water. Thus, the AGC stock in 2010 was reduced to a certain degree in this area as compared to 2004 .

\subsection{Causes of change in AGC stock distribution}

\subsubsection{Precipitation factor}

Water plays a significant role during the process of vegetation growth (Yan et al., 2013). In this study, the annual precipitation data from 2004 to 2010 in Xi'an city (Shaanxi Provincial Bureau of Statistics, 2005- 


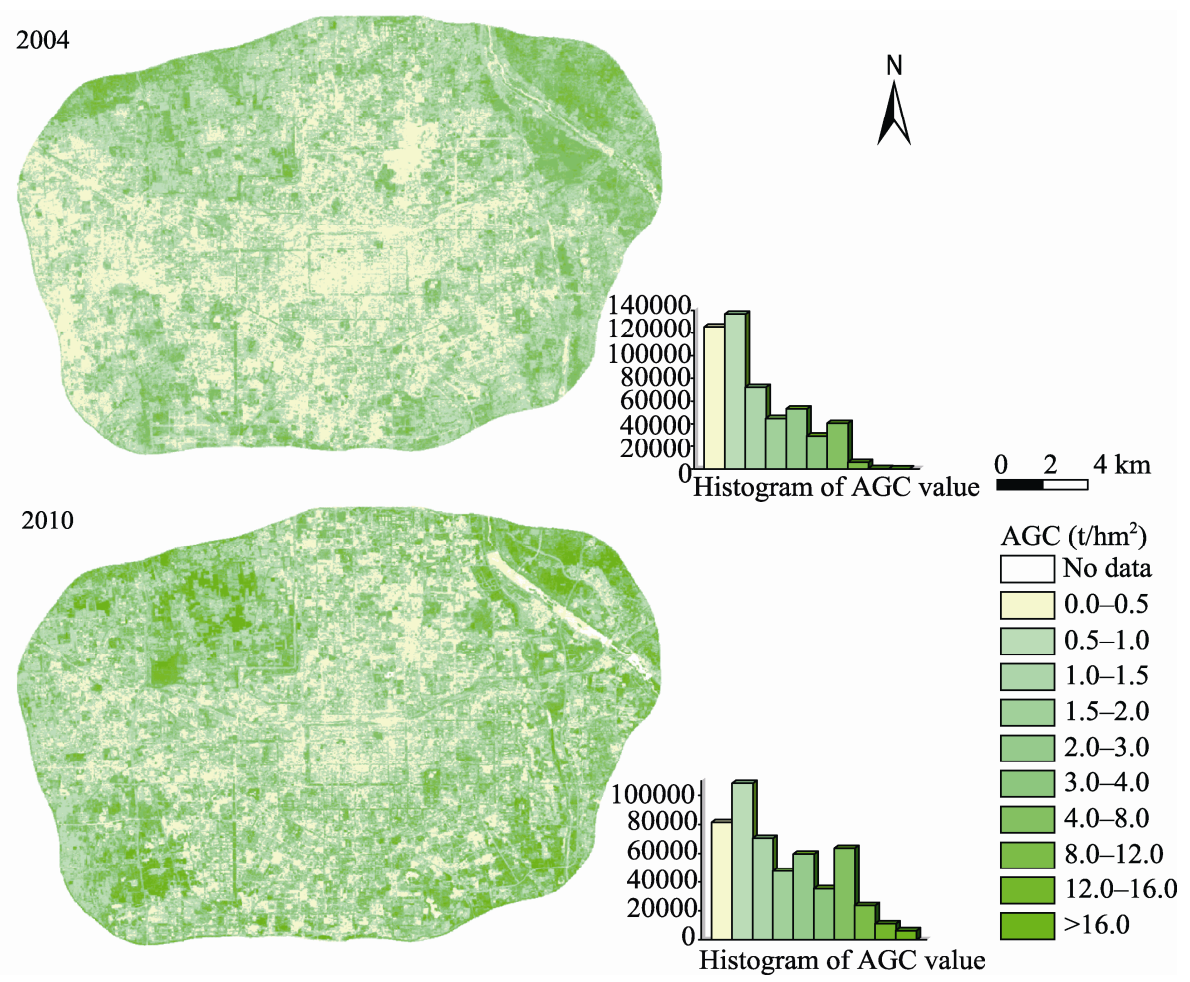

Fig. 3 Distributions of AGC stock in the study area from 2004 to 2010

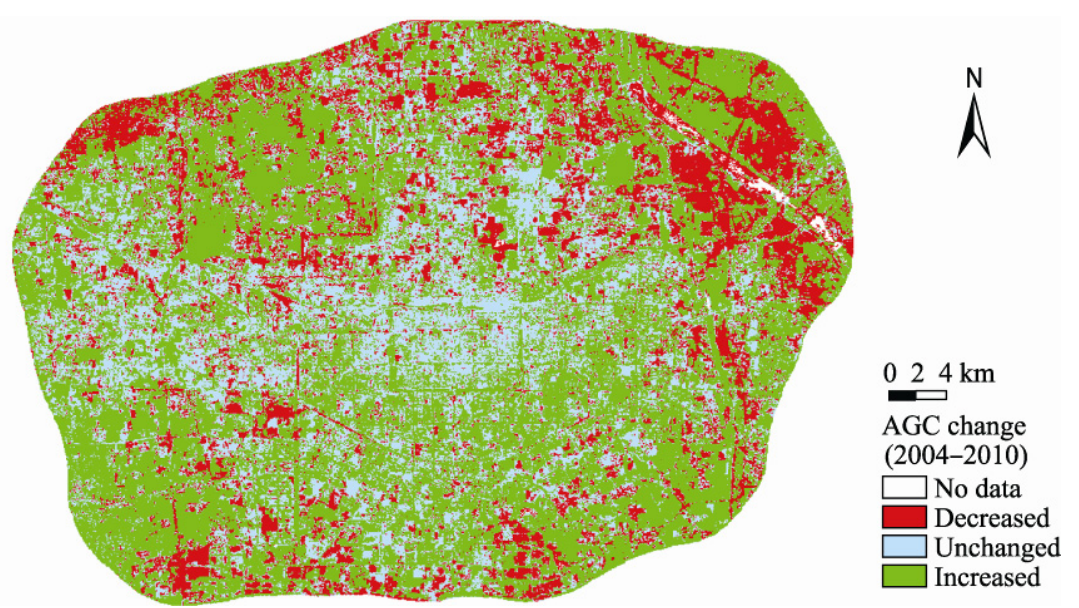

Fig. 4 Map of spatial AGC stock change in the study area from 2004 to 2010

2006; Shaanxi Provincial Bureau of Statistics and NBS Survey Office in Shaanxi, 2007-2011) were referred. By analyzing the changes of total AGC stock and precipitation from 2004 to 2010 (Fig. 5), it was found that no obvious variety regulation existed in annual precipitation and significant correlation between the two parameters was not observed. Therefore, precipitation was not a crucial factor in the process of influencing the changes of AGC stock. Roerink et al. (2003) pointed out that the vegetation is highly sensitive to yearly precipitation changes in dry areas (deserts), while in very humid areas, precipitation is not the major limiting factor to vegetation development. In our study area, precipitation was not a key factor to vegetation development, which was due to the irrigation in urban green space. 


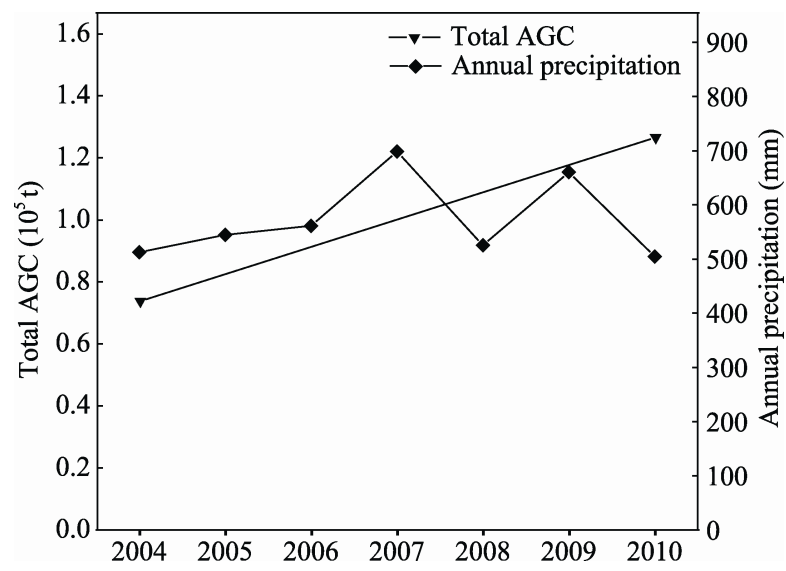

Fig. 5 Changes of total aboveground carbon (AGC) stock and annual precipitation in Xi'an city from 2004 to 2010

3.3.2 The effects of policy orientation and major urban ecological greening projects

On a regional scale, urban green space system planning as well as related policies and regulations play a guiding and mandatory role in urban greening and changes in green space landscape. The area of urban green space in Xi'an increased from $4,502 \mathrm{hm}^{2}$ in 2004 to $12,140 \mathrm{hm}^{2}$ in 2010, and the green coverage rate of built-up areas increased from $30.06 \%$ in 2004 to $37.50 \%$ in 2010 (Xi' an Municipal Bureau of Statistics, 2005; Xi'an Municipal Bureau of Statistics and NBS Survey Office in Shaanxi, 2011).

In addition, major urban greening projects produced an important impact on the distribution pattern of urban green space AGC stock in Xi'an. For example, the Chan-Ba Ecological District, built in 2004 at the northeast corner of Xi'an, is one of the key projects during the "Eleventh Five-Year Plan" period. It is where the 2011 World Horticultural Exposition was held and also where the first national wetland park in Northwest China was built. Substantial changes in urban green space AGC stock in northeast Xi'an occurred precisely because of the construction of the Chan-Ba Ecological District (Fig. 4). Increase in urban green space AGC stock in southeast Xi'an may be related to the planning and construction of several "ruins" parks in this region over the past years. Green space AGC stock in northwest Xi'an also changed notably (Fig. 4), and this is where the Han Chang'an City Ruins are located. As a capital city during thirteen historical dynasties, Xi'an has invested a large amount of effort in protecting an- cient ruins. In recent years, the city government has increased its investments in the protection of the Han Chang'an City Ruins, and vegetation growth both within and surrounding the ruins has improved gradually. Furthermore, in 2012, the Xi'an government launched a plan to protect the Qin Epanggong ruins in west Xi'an. With the implementation of these key construction projects, the distribution of urban green space AGC stock across Xi'an will become even more balanced in the future.

\subsubsection{Transplanting big trees into the city}

For the current study, "big trees" mainly refer to tall or old trees with a certain ornamental value. They are an important component of the green space system. The use of big trees in urban greening provides an instant and substantial greening effect, and these trees play an important role in urban ecosystems. Studies have shown that the carbon storage of large trees is much greater than that of small trees (Ren et al., 2011). For example, the study by Nowak (1993) pointed out that the carbon stock of big trees was 1,000 times that of small trees. Currently, "transplanting big trees into the city" is one of the focuses of landscape construction in various cities in China. Many medium and large cities have used a large number of big trees in urban greening, and big trees have become the main carrier of green space and carbon stock in cities. In 2008, Xi'an launched the project of "transplanting 10,000 big trees to the ancient city", and since then, 16,000 big trees have been transplanted along streets and in parks. This effectively improved the green coverage rate and substantially contributed to increasing urban space carbon stock.

\subsubsection{Impact of major events}

A "major event" often refers to an event that produces significant social and economic impact on a city or a country. Major events provide important opportunities to promote contemporary urban development and environmental landscape construction; they play a key role in the construction and improvement of urban public green space. The $30^{\text {th }}$ World Horticultural Exposition held in Xi'an in 2011 brought a new upsurge in urban greening and new opportunities for urban landscape development. Xi'an strengthened the construction of urban greening projects to better host the exposition. Since October 2008, more than 98,000 large trees, $1.36 \times 10^{6}$ trees over $8 \mathrm{~cm}$ in $\mathrm{DBH}$, 
$4.717 \times 10^{6}$ flowering trees and $22.46 \times 10^{6}$ shrubs were planted, resulting in a total of $16.66 \times 10^{6} \mathrm{~m}^{2}$ newly added green space. This strongly promoted the rapid development of urban landscape in Xi'an, thus producing an important impact on the increase of the AGC stock in the urban green space of Xi'an.

\section{Conclusions}

To better understand the role of urban green space in reducing $\mathrm{CO}_{2}$ emission, the present study estimated AGC stock in the urban green space of Xi' an in 2004 and 2010 based on field survey data and Landsat TM remote sensing data. Subsequently, a map of changes in the spatial and temporal patterns of AGC stock was plotted, and the causes of these changes were analyzed. The results showed that NDVI was the most reliable to estimate AGC stock in urban green space of Xi'an. From 2004 to 2010, the AGC stock in the urban green space of Xi'an increased from 73,843 to 126,621 t, and carbon densities in 2004 and 2010 were 1.62 and $2.77 \mathrm{t} / \mathrm{hm}^{2}$, respectively. Precipitation was not a key factor to affect the changes of AGC stock in the urban green space of Xi'an. Policy orientation, major ecological greening projects such as "transplanting big trees into the city" and the World Horticultural Exposition were found to have an important impact on the changes in the spatiotemporal patterns of AGC stock. The results of this study will provide insights into understanding the carbon balance of urban ecosystems and the information can be used by urban planners to better manage vegetation in urban green space to establish low carbon cities.

To improve the accuracy of carbon stock estimation in urban green space, more efforts should be made to establish allometric models in further studies. Furthermore, only aboveground carbon stock of the total urban green space was estimated in this study; the allocation of AGC storage for trees, shrubs and herbs also needs to be taken into account for more accurate estimation.

\section{Acknowledgements}

This research was supported by the Forestry Research Foundation for the Public Service Industry of China (200904004). We thank Min ZHANG, QiSheng HAN, YanZheng YANG and all the people who helped with the fieldwork and data analysis.

\section{References}

Ajtay G L, Ketner P, Duvigneaud P. 1979. Terrestrial production and phytomass. In: Bolin B, Degens E T, Kempe S, et al. The Global Carbon Cycle. New York: John Wiley \& Sons, SCOPE Report No. 13: $129-182$.

Barati S, Rayegani B, Saati M, et al. 2011. Comparison the accuracies of different spectral indices for estimation of vegetation cover fraction in sparse vegetated areas. The Egyptian Journal of Remote Sensing and Space Science, 14(1): 49-56.

Baret F, Guyot G. 1991. Potentials and limits of vegetation indices for LAI and APAR assessment. Remote Sensing of Environment, 35(2-3): 161-173.

Birth G S, McVey G R. 1968. Measuring the color of growing turf with a reflectance spectrometer. Agronomy Journal, 60(6): 640-643.

Chang X X, Che K J, Song C F, et al. 1997. Biomass and nutrient element accumulation of Sabina prezewalskii forest community. Journal of Northwest Forestry College, 12(1): 23-28. (in Chinese)

Chow P, Rolfe G L. 1989. Carbon and hydrogen contents of short rotation biomass of five hardwood species. Wood and Fiber Science, 21(1): 30-36.

Du Y, Teillet P M, Cihlar J. 2002. Radiometric normalization of multitemporal high-resolution satellite images with quality control for land cover change detection. Remote Sensing of Environment, 82(1): 123-134

Guan D S, Chen Y J, Huang F F. 1998. The storage and distribution of carbon in urban vegetation and its roles in balance of carbon and oxygen in Guangzhou. China Environmental Science, 18(5): 437-441. (in Chinese)

He H Z, Huang L H, Duan X, et al. 2007. Study on biomass in main afforestation tree species of the second ring forest-belt of Guiyang. Guizhou Science, 25(3): 33-39. (in Chinese)

Houghton R A. 2005. Aboveground forest biomass and the global carbon balance. Global Change Biology, 11(6): 945-958.

Huete A R. 1988. A soil-adjusted vegetation index (SAVI). Remote Sensing of Environment, 25(3): 295-309.

Huete A R, Liu H Q, Batchily K, et al. 1997. A comparison of vegetation indices global set of TM images for EOS-MODIS. Remote Sensing of Environment, 59(3): 440-451.

Ji L, Peters A J. 2007. Performance evaluation of spectral vegetation indices using a statistical sensitivity function. Remote Sensing of Environment, 106(1): 59-65.

Jiang Z Y, Huete A R, Didan K, et al. 2008. Development of a two-band enhanced vegetation index without a blue band. Remote Sensing of Environment, 112(10): 3833-3845.

Jo H K, McPherson E G. 1995. Carbon storage and flux in urban residential greenspace. Journal of Environmental Management, 45(2): 109-133.

Jo H K. 2002. Impacts of urban greenspace on offsetting carbon emissions for middle Korea. Journal of Environmental Management, 64(2): 115-126.

Johnston M H, Homann P S, Engstrom J K, et al. 1996. Changes in ecosystem carbon storage over 40 years on an old-field/forest landscape in east-central Minnesota. Forest Ecology and Management, 83(1-2): 17-26. 
Kanniah K D, Muhamad N, Kang C S. 2013. Remote sensing assessment of carbon storage by urban forest. IOP Conference Series: Earth and Environmental Science. IOP Publishing, 18(1): 012151.

Karl T R, Nicholls N, Gregory J. 1997. The coming climate. Scientific American, 276(5): 78-83.

Li F, Jiang L, Wang X F, et al. 2013. Estimating grassland aboveground biomass using multitemporal MODIS data in the West Songnen Plain, China. Journal of Applied Remote Sensing, 7(1), 073546, doi:10.1117/1.JRS.7.073546.

Li H K, Lei Y C. 2010. Estimation and Evaluation of Forest Biomass Carbon Storage in China. Beijing: Chinese Forestry Press. (in Chinese)

Li X N, Guo Q X, Wang X C, et al. 2010. Allometry of understory tree species in a natural secondary forest in northeast China. Scientia Silvae Sinicae, 46(8): 22-32. (in Chinese)

Li Z H, He L X, Zhou Y P, et al. 1996. Studies of biomass and productivity of Metasequoia glyphostrobodes plantation. Journal of Central-South Forestry University, 16(2): 47-51. (in Chinese)

Liu G H, Fu B J, Fang J Y. 2000. Carbon dynamics of Chinese forests and its contribution to global carbon balance. Acta Ecologica Sinica, 20(5): 733-740. (in Chinese)

Lu X Y, Chen S X, Li M Q, et al. 1990. Resarch on the biomass of Paulownia. Forest Research, 3(5): 421-426. (in Chinese)

Ma Q Y. 1989. A study on the biomass of Chinese pine forests. Journal of Beijing Forestry University, 11(4): 1-10. (in Chinese)

McPherson E G. 1998. Atmospheric carbon dioxide reduction by Sacramento's urban forest. Journal of Arboriculture, 24(4): 215-223.

Melillo J M, Callaghan T V, Woodward F I, et al. 1990. Effects on ecosystems. Climate Change: The IPCC Scientific Assessment, 283-310.

Myeong S, Nowak D J, Duggin M J. 2006. A temporal analysis of urban forest carbon storage using remote sensing. Remote Sensing of Environment, 101(2): 277-282.

Nowak D J. 1993. Atmospheric carbon reduction by urban trees. Journal of Environmental Management, 37(3): 207-217.

Nowak D J. 1994. Atmospheric carbon dioxide reduction by Chicago's urban forest. In: McPherson E G, Nowak D J, Rowntree R A. Chicago's Urban Forest Ecosystem: Results of the Chicago Urban Forest Climate Project. USDA Forest Service General Technical Report NE-186. Radnor, PA: US Department of Agriculture, Forest Service, Northeastern Forest Experiment Station, 83-94.

Nowak D J, Crane D E. 2002. Carbon storage and sequestration by urban trees in the USA. Environmental Pollution, 116(3): 381-389.

Olson J S. 1970. Carbon cycles and temperate woodlands. In: Reichle D E. Analysis of Temperate Ecosystems. Berlin Heidelberg: Springer-Verlag, Ecological Studies Volume 1: 226-241.

Qi J, Chehbouni A, Huete A R, et al. 1994. A modified soil adjusted vegetation index. Remote Sensing of Environment, 48(2): 119-126.

Ren Y, Wei X, Wei X H, et al. 2011. Relationship between vegetation carbon storage and urbanization: a case study of Xiamen, China. Forest Ecology and Management, 261(7): 1214-1223.
Roerink G J, Menenti M, Soepboer W, et al. 2003. Assessment of climate impact on vegetation dynamics by using remote sensing. Physics and Chemistry of the Earth, 28(1-3): 103-109.

Rouse J W Jr, Haas R H, Schell J A, et al. 1974. Monitoring vegetation systems in the great plain with ERTS. In: Freden S C, Mercanti E P, Becker M A. Third Earth Resources Technology Satellite-1 Symposium-Volume I: Technical Presentations. NASA SP-351. Washington, DC: NASA, 309.

Schlerf M, Atzberger C, Hill J. 2005. Remote sensing of forest biophysical variables using HyMap imaging spectrometer data. Remote Sensing of Environment, 95(2): 177-194.

Schott J R, Salvaggio C, Volchok W J. 1988. Radiometric scene normalization using pseudoinvariant features. Remote Sensing of Environment, 26(1): 1-16.

Shaanxi Provincial Bureau of Statistics. 2005-2006. Statistical Yearbook of Shaanxi. Beijing: China Statistics Press. (in Chinese)

Shaanxi Provincial Bureau of Statistics, NBS Survey Office in Shaanxi. 2007-2011. Statistical Yearbook of Shaanxi. Beijing: China Statistics Press. (in Chinese)

Sivrikaya F, Baskent E Z, Bozali N. 2013. Spatial dynamics of carbon storage: a case study from Turkey. Environmental Monitoring and Assessment, 185(11): 9403-9412.

USDA Forest Products Laboratory. 1952. Chemical Analysis of Wood. Madison, Wisconsin: USDA Forest Service Forest Products Laboratory, Technical Note 235 .

Wang Q, Adiku S, Tenhunen J, et al. 2005. On the relationship of NDVI with leaf area index in a deciduous forest site. Remote Sensing of Environment, 94(2): 244-255.

Wang R S, Fang J Y, Gao L, et al. 1996. The Hotpoints for Modern Ecology Research. Beijing: China Science and Technology Press. (in Chinese)

Xi'an Municipal Bureau of Statistics. 2005. Xi'an Statistical Yearbook. Beijing: China Statistics Press. (in Chinese)

Xi'an Municipal Bureau of Statistics, NBS Survey Office in Shaanxi. 2011. Xi'an Statistical Yearbook. Beijing: China Statistics Press. (in Chinese)

Yan F, Wu B, Wang Y J. 2013. Estimating aboveground biomass in Mu Us Sandy Land using Landsat spectral derived vegetation indices over the past 30 years. Journal of Arid Land, 5(4): 521-530.

Yang L. 2011. The build study of Populus tomentosa biomass model in Beijing Daxing District. Hebei Journal of Forestry and Orchard Research, 26(4): 345-348. (in Chinese)

Yao Z Y, Liu J J. 2014. Models for biomass estimation of four shrub species planted in urban area of Xi'an City, Northwest China. Chinese Journal of Applied Ecology, 25(1): 111-116. (in Chinese)

Zhao M, Kong Z H, Escobedo F J, et al. 2010. Impacts of urban forests on offsetting carbon emissions from industrial energy use in Hangzhou, China. Journal of Environmental Management, 91(4): 807-813.

Zhu X W, Xiao Y, Cai W C. 1988. Study on biomass of Populus davidiana natural secondary forest. Science and Technology of Qinghai Agriculture and Forestry, (1): 30-34. (in Chinese) 